\title{
ThamRobot: An Automated Robotic System to Play Thammattama
}

\author{
M.A.S.T Goonatilleke \\ Lecturer (Probationary) \\ General Sir John Kotelawala Defence University \\ Colombo, Sri Lanka
}

\author{
B Hettige \\ Senior Lecturer \\ General Sir John Kotelawala Defence University \\ Colombo, Sri Lanka
}

\begin{abstract}
Sri Lanka has a precious traditional drum music culture that is mainly based on traditional drums. At present, this drum culture is in decline due to a lack of talented drum players. As a result, many Buddhist temples are facing a serious and tragic problem. This article presents the design and implementation of a robotic system named ThamRobot contains two robotic arms that were designed to play pre-programmed three drum tunes of the Thammattama correctly and efficiently like a drum player without any intervention of a human. In the research, nine major characteristics factors of the Thammattama such as music notes, drum locations, approximate stress, frequencies, pitch, drum type, number of sticks, playing technique, distance from stick to drum face were identified. The entire system is comprised of four main modules named motion module, user-operation module, processing module, power supply module. Finally, the system has been tested in a laboratory environment and encouraging results were obtained.
\end{abstract}

Keywords: Robotic Arms, Musical Robots, Traditional Drums, Thammattama, Automated Systems, Microcontrollers, Robots

\section{INTRODUCTION}

Sri Lanka has a unique, beautiful, and great traditional music culture that has a long history of over 2,500 years [1]. The traditional music culture of Sri Lanka is mainly based on traditional musical instruments that are endemic to the country. The ancient violin that was created by the great King Ravana, "Hakgediya" (the conch), "pantheruwa" (the tambourine), and different types of drums are considered the oldest musical instruments in Sri Lanka. Traditional musical instruments are an invaluable and inseparable part of the music culture of Sri Lanka and traditional drums are considered the king of local music instruments [2]. Ancient Sri Lanka had more than sixty types of traditional drums and at present, about ten drums are currently using for religious, cultural, ritualistic, and aesthetic performances. Accordingly, people often use traditional drums such as "Getaberaya", "Yakberaya", "Dawula", "Thammattama", "Rabana", "Bummadiya", "Udekkiya", "Dandu-Beraya" for various purposes and among them, "Getaberaya", "Yakberaya", "Dawula" and "Thammattama" are considered as the four major drums in Sri Lanka [3]. These drums are mostly used by the Buddhist people in Sri Lanka for their religious activities. Therefore, this tradition has been become an integral part of the culture of the country and also a pride in Sri Lanka [4].

The drum culture of Sri Lanka is mainly classified into three categories as "Udarata Bera Wadana Kalawa" (The art of the up-country drumming), "Pahatharata Bera Wadana Kalawa" (The art of the low-country drumming), and "Sabaragamu Bera Wadana Kalawa" (The art of the Sabaragamuwa province drumming) [5]. The art of the up-country drumming deals with three drums such as "Getaberaya", "Dawula" and "Thammattama" while the art of the low-country drumming deals with "Yakberaya" and "Dawula". The art of the Sabaragamuwa province drumming uses "Dawula" and "Thammattama" as main drums [6].
These traditional drums have a unique vibrant beat of the rhythm and a unique style of drumming [7]. Not only that but also, these drum rhythm beats and drumming styles are not included in the source material and are transmitted from generation to generation. Accordingly, there are traditional families that are dedicated to play drums from ancient times. These families carry playing techniques, drum notes from generation to generation.

Ancient Sri Lanka had more than sixty traditional drums that are endemic to the country but ten of them are currently in use [8]. This is because this precious traditional drum music culture is gradually dying out as it faces a lot of problems unfortunately due to a lack of talented performers. The situation escalated very quickly due to the modern social transformation and their profession is not properly recognized. Besides, there is no formal recognition, proper appreciation for these drummers and they face a lot of problems financially. Although this art is a source of great pride to Sri Lanka, there is no state patronage has been received for this worthy cause. As a tragic consequence of these causes, these traditional drummers are standing back from their traditional occupation and seeking other employment.

In the face of the current unfortunate situation, another tragic thing is happening gradually. That is, the number of talented drummers who play Thammattama is gradually decreasing [9]. The main reason for this situation is that the drumming of the Thammattama is extremely complex compared to other drums. There is an opinion of the ancients that the ability to play this drum comes from birth as its playing technique is very complex. The importance of the Thammattama is that it is used for all the three drum cultures in Sri Lanka and it has become an indispensable drum in Buddhist temples. Therefore, the decline of Thammattama, one of the foremost 
traditional drums in Sri Lanka is finally coming to an end very unfortunately and as the current solution, many Buddhist temples are using recorded music. This method is not a successful substitution as it does not produce the natural and the real sound of the Thammattama and there is a huge difference between the real sound and the recorded sound. While there are no advanced tools in the country to process this recorded music and this method has become a very unsuccessful alternative.

Many issues can be solved in a practicable way using new technologies and the article is going to discuss an automated robotic system named ThamRobot that was designed to play the Thammattama. This robotic system has two robotic arms that are holding the two playing sticks of the Thammattama and play three types of standard drum tunes very accurately, correctly, and efficiently without any intervention of a humanlike a drum player. The advantage of this system is, this has been programmed to play three common drum tunes that are very frequently play at Buddhist temples where there is a shortage of Thammattama drummers.

\section{THAMMATTAMA: A TRADITIONAL DRUM IN SRI LANKA}

Thammattama is an extremely exceptional traditional drum that is endemic to Sri Lanka [10]. It is one of the four major drums in Sri Lanka and a very special drum due to various reasons. This drum performs a great service in Buddhist religious occasions, traditional occasions as well as in communication. This drum has been become very special as it belongs to all the three cultures in Sri Lanka named upcountry music tradition, low-country music tradition, and Sabaragamuwa music tradition. Unlike other drums in the country, this drum has two plane drum faces that are clasped together. Accordingly, older writers have called this drum "Pokuru-Beraya" or "Twin-Drum". However, these drums are different in size and one drum is larger than the other drum. The larger drum is named "Mandama" which produces low sounds while the smaller drum is named "Handabeya" which produces high sounds.

The drum bodies of the Thammattama are widely made using very strong wood such as "Ehela", "Kohomba", Jak and "Gansooriya". But today due to the scarcity of these woods, well-matured coconut wood is also used to make the drum bodies. The heights of the drum bodies are approximately 7 inches. The face diameter of the Mandama is 10.5 inches while the diameter of the Handabeya is 7 inches [11]. Drum membranes are used to cover the faces of the drums, and they are made of tempered animal skins. The types of animal skins used to cover the drum faces vary from drum to drum, and beef skins are used as the drum membrane of the Thammattama. The drum face of the Mandama is covered with a thick beef while the drum face of the Handabeya is covered with a less thickened beef skin. The thickness of the animal skin, the area of the drum faces mainly affect the difference in sounds. Thammattama is played with the use of two special sticks named "Kadippu" that are made of well- matured wood such as "Kirindi" or "Rathmal" [12]. Figure 1 and 2 show the measurements and parts of the Thammattama respectively.

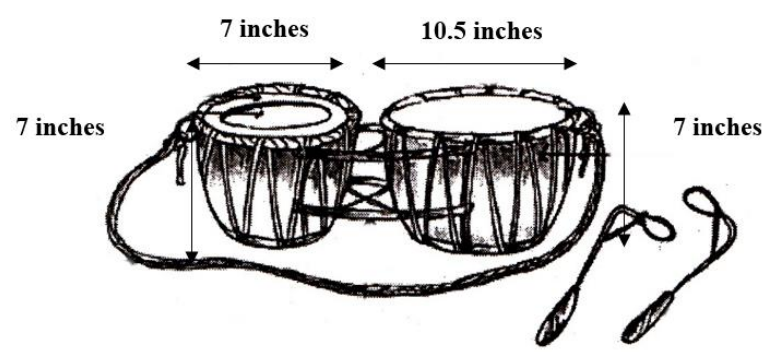

Figure 1. Measurements of the Thammattama
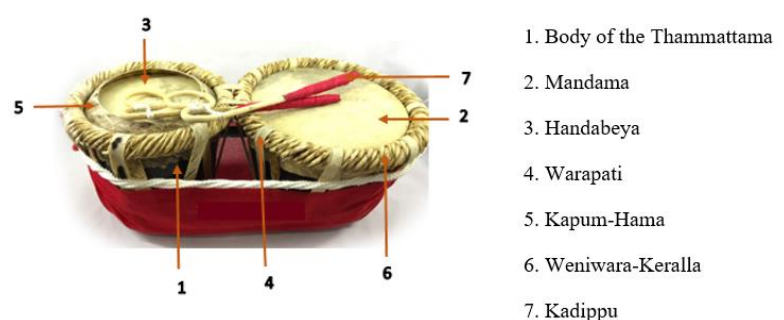

Figure 2. Parts of the Thammattama

Thammattama mainly produces ten music notes using Handabeya, Mandama, and also using both drums. The Mandama produces three notes such as "Don", "Thon" and "Kun" while Handabeya produces four notes such as "Kita", "Kruu" "Thari" and "Thath". The three music notes such as "Jen", "Raj" and "Digi" are produced using both drums. However, the playing technique, music patterns, sound variations of the Thammattama is complex compared with other drums in the country. Table 1 shows the details of the playing techniques of the Thammattama

At the first step of the research, characteristic factors of the Thammattama have been identified with the help of two talented Thammattama players and frequency counter. Table 2 shows the basic characteristic factors of the Thammattama. These basic characteristics include the drum type, number of sticks, and playing technique. When consider the drum type, the notes can be produced either using one of the two drums of the Thammattama or both drums. The notes such as "Don", "Thon" and "Kun" are produced using the Mandama (larger drum). In addition, all of these three notes are produced by hitting on the drum face of the Mandama only one time. The Handabeya produces four notes as "Kita", "Kruu" "Thari" and "Thath". The notes "Kita", "Kruu" "Thari" are produced by hitting the drum face of the Handabeya by using two sticks one after the other very quickly. The note "Thath" is produced by hitting the face of the Handabeya by using one stick at one time. The notes "Jen", "Raj" and "Digi" are produced by using both of the drums. Among them, "Jen", "Raj" sounds are produced by hitting the both drum faces by two sticks 
simultaneously while "Digi" sound is produced by hitting the two drum faces by two sticks one after the other.

Table 1. Playing Techniques of the Thammattama

\begin{tabular}{|l|c|c|}
\hline Music Note & $\begin{array}{c}\text { Playing } \\
\text { Technique } \\
\text { Number }\end{array}$ & $\begin{array}{l}\text { Playing Technique of } \\
\text { the Thammattama }\end{array}$ \\
\hline Thon & 1 & \\
\hline Kun & & \\
Kruu (K-ruu) & & \\
\hline Thari (Tha-ri) & & \\
\hline Thath & & \\
\hline Digi (Di-ta) & & \\
\hline
\end{tabular}

Table 2. Basic Characteristic Factors of the Thammattama

\begin{tabular}{cccc} 
Music Note & Drum & Number of Sticks & Playing Technique \\
\hline Don & Mandama & One & Once \\
Thon & Mandama & One & Once \\
Kun & Mandama & One & Once \\
Kita & Handabeya & Two & One after other \\
Kruu & Handabeya & Two & One after other \\
Thari & Handabeya & Two & One after other \\
Thath & Handabeya & One & Once \\
Gen & Both & Two & Simulataneous \\
Raj & Both & Two & Simulataneous \\
Digi & Both & Two & One after other \\
\hline
\end{tabular}

Table 3 shows the advanced characteristic factors of the Thammattama including the distance between the stick and drum face $\left(\mathrm{d}_{\mathrm{sd}}\right)$, frequency of the notes, pitch, drum location and approximate amount of stress applied on the drum face.

Table 3. Advanced Characteristic Factors of the Thammattama

\begin{tabular}{|c|c|c|c|c|c|}
\hline Music Not & Distance between drum face and stick & Frequency & Pitch & Drum Location & \\
\hline & $30 \mathrm{~cm}$ & $80 \mathrm{~Hz}$ & Very Low (Bass) & Middle & Very High \\
\hline Thon & $20 \mathrm{~cm}$ & $92 \mathrm{~Hz}$ & Low (Bass) & Middle & High \\
\hline & $\begin{array}{l}10 \mathrm{~cm} \\
20 \mathrm{~m}\end{array}$ & $\begin{array}{l}10 \mathrm{~Hz} \\
{ }_{130 \mathrm{~Hz}}\end{array}$ & Low (Tenor) & $\begin{array}{l}\text { Middle } \\
\text { Nididle }\end{array}$ & Low \\
\hline $\begin{array}{l}\text { Sita } \\
\text { Krum }\end{array}$ & $20 \mathrm{~cm}$ & 1300 & 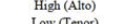 & $\begin{array}{l}\text { Middle } \\
\text { Yidle. }\end{array}$ & \\
\hline $\begin{array}{l}\text { Krum } \\
\text { Thari }\end{array}$ & $\begin{array}{l}5 \mathrm{~cm} \\
1 \mathrm{~cm}\end{array}$ & $\begin{array}{l}110 \mathrm{~Hz} \\
112 \mathrm{~Hz}\end{array}$ & $\begin{array}{l}\text { Low (Cenor) } \\
\text { High (Alto) }\end{array}$ & $\begin{array}{l}\text { Midale } \\
\text { Widte }\end{array}$ & $\begin{array}{l}\text { Low } \\
\text { Hivh }\end{array}$ \\
\hline Thath & $30 \mathrm{~cm}$ & ${ }_{157 \mathrm{~Hz}}$ & Very Hinh (Soprano) & Middle & $\begin{array}{l}\text { Hiten } \\
\text { Very High }\end{array}$ \\
\hline Gen & $15 \mathrm{~cm}$ & $95 \mathrm{~Hz}$ & High (Alto) & Middle & Very High \\
\hline Raj & $10 \mathrm{~cm}$ & $91 \mathrm{~Hz}$ & Low (Tenor) & Middle & Low \\
\hline Digi & $10 \mathrm{~cm}$ & $122 \mathrm{~Hz}$ & High (Alto) & Middle & High \\
\hline
\end{tabular}

\section{RELATED WORKS}

Robotics is an interdisciplinary branch of the engineering and science industry that covers mechanical, electronic, information, computer science, and other sectors [13]. Robotic technology is used to build machines that can replace people to perform human activities. Robots are used in many different environments and for many different applications [14]. Although they differ in application and form, they all share three fundamental fields as mechanical engineering, electrical engineering, and computer science [15].

Robotic arms are considered as one of the major and the most popular mechanical parts in robotic systems. It can be further explained as a mechanical product or a set of rigid jointed bodies able to take different configurations [16]. Robotic arms have been become very valuable and popular interim due to some common reasons. They are widely used in situations and places where humans are not able to work such as polluted air zones, high temperatures, heavy weight lifting, etc.

Therefore, there are different types of robotic arms available in the market that can be used for specific purposes. They have been very famous because of increased efficiency, higher quality, improved working environment, increased profitability, longer working hours, and prestige [17]. The robotic arms have some common parameters such as the number of axes, degree of freedom, working envelope and working space covering the arm, kinematics, payload, speed and acceleration, accuracy and repeatability, movement control and arm drive, etc [18].

The robotic arms can be developed using several technologies and wireless technology is one of them [19]. MR-999-E is a wireless robotic arm that can perform five separate movements such as grab or release, lift or lower, rotate wrist, and pivot sideways using five servo-motors [20]. The architecture of this robotic arm system has been comprised of three main components such as a transmitter, receiver, computer, and robotic arm. The transmitter has been connected to the computer and the receiver has been connected to the robotic arm interface. The graphical user interface (GUI) of the arm has been modeled using SolidWorks 2005 software and implemented using Visual Basic environment. 
Automation technology is also a very common and a rapidly growing technology in the field of industries and robotics that is a type of technology by which a process or a procedure is performed with minimal human assistance [21]. Aparnathi and Rajendra have developed a six axes robotic arms to perform various actions in industry. The architecture of the arm consists of manipulator with end effecter, controller as commander, power supply, feedback mechanism, and sensor feedback [22].

Combination of wireless technology and automation technology can lead to invent better robotic arms and highperformance robotic systems. These types of practical arms are very essential to perform actions in warehouses. Nobutaka Kimura and others have developed an automated mobile dualarm robot to pick and place objects in warehouses [23]. It is an Epson 6-axis robot arm that has a long reach of about 90 $\mathrm{cm}$. It can lift and pick $2 \mathrm{~kg}$ products and uses $200 \mathrm{~V}$ power source. The arms have an RGBD camera and an RGB camera to recognize the kind, position, the orientation of the products.

Niranjan and other have designed a robotic arm to perform tasks by its physical strength using Arduino-Uno, flex sensor, Wi-Fi module and also servo-motor [24]. Basically, inputs are taken from the outside environment by the flex sensor and then a controller calculate how much the fingers of the arm have to be moved to grab a particular object. As the next step, the servo-motors perform the task with the help of the controller.

There many robotic arms have been designed for various applications such as agriculture, military, medical field and etc. "Animator" is a robotic arm that was designed by rahman and others to overcome from many challenges in daily life [25]. This arm generates a realistic velocity distributions to manilpulate several types of motions. and uses the mechanism and the mechanical structure of ASR K-250 to perform human-like manipulation motions. This arm has been implemented and tested successfully for the 4 degrees of freedom (DOF). Besides, Many robotic arms have been designed for agriculture field and Megalingam and others have developed a robotic arm to support agriculture industry that is controlled by depth sensors [26]. This robotic system has five main blocks such as Microsoft Kinect sensor, portable computer, API (Microsoft Kinect SDK), microcontroller and actuators and the operations that are performed by the robotic arm are controlled by these five blocks. Basically, the input to the system is entered from the physical world through the sensors and as the next step, these data are processed by portable computer, API and microcontroller. As the final step, the processed data will be given as the output in the form of motion of the actuators of the robotic arm.

At present, robotics is created based on the application area and musical robots are evolving day by day. Musical robots can now be used to play musical instruments very well and easily without any players. As a starting point Kapur has done a review on the history of robotic musical instruments [27]. Most of the robots in the past have been designed with the use of motors, gears and solenoids. Besides, he has discussed several musical robots and their technologies such as piano robots, percussion robots, woodwind robots and strings robots. Piano robot is one of the examples for an automatic musical instrument. Designers have designed these robots by using punched cards that give commands to the hammers in the piano to create chords, melodies and harmonies. A French innovator, Fourneaux, invented the first piano player named "Pianista" in 1863. After that, in 1896, Edwin Scott Votey invented the "Pianola", a device that is similar to the piano and performed pressing keys using wooden fingers. Then, in 1897, Edwin Welte designed a piano player using loom technology. In 1980 Trimpin designed "Contraption Instant Prepared Piano 71512" that has mechanically bowing, plucking, and other manipulations of the strings. This system has been controlled through a remote-controlled MIDI device.

Sobh and Wang have developed a robot musician band that was established at the Bubble Theatre of the Arnold Bernhardt Center of University of Bridgeport [28]. The significance of this band is, each one who plays an instrument is a robot. Accordingly, they play real musical instruments through the usage of several mechanical devices like servo-motors and solenoids. The research has been linked with three main areas such as; robotic technology, computer science and music and each robot in the band has been constructed with hardware and software design and adopted a three-module architecture consists of a software module, a control module and a motion module.

"A Comparison of Solenoid-Based Strategies for Robotic Drumming" is a research done by Kapur and others that was related to a robot named "MahaDeviBot" [29]. This musical robot is a custom-built 12-armed MIDI-controlled mechanical device that plays a variety of Indian folk instruments. Besides, it includes some other instruments like bells, shakers and frame-drums to decorate music. "MahaDeviBot" has been designed with the use of solenoids and finally, it has been evaluated using a haptic feedback system.

Thambot is a robotic approach that was proposed for the drum named Thammattama which is one of the traditional drum in Sri Lanka. Accordingly, the authors have done a research to find four characteristic factors of the Thammattama [30]. As the next step of the research, they have developed a robotic system to play one standard drum beat using two robotic arms [31]. The overall system consisted of six modules named power module, a processing module, solenoid control module, servo-motor controller module, input module and display module. Finally, the developed system has been successfully tested with human players.

\section{METHODOLOGY}

ThamRobot is an automated robotic system that was designed to play the Thammattama which is one of the traditional drums in Sri Lanka. Mainly, the system has two robotic arms that are used to play the Thammattama. These two robotic 
arms are made of Aluminium metal. At the end of the each arm the stick of the Thammattama named Kadippu have been attached and invented using solenoids, servo-motors. These two arms are capable of working along two axis such as $\mathrm{X}$ axis and $\mathrm{Y}$ axis. The system has been programed using the PIC 16F877A microcontroller and microchip technology [32]. The entire system of the ThamRobot is a combination of main four modules such as power supply module, processing module, motion module and user operation module. The system has been designed to play three pre-programmed standard drum tunes correctly, efficiently and accurately without any intervention of a human like a drum player and depicts the behavior of the open loop control system. The figure 3 shows the overall architecture of the ThamRobot system and brief introduction of each module is given below.

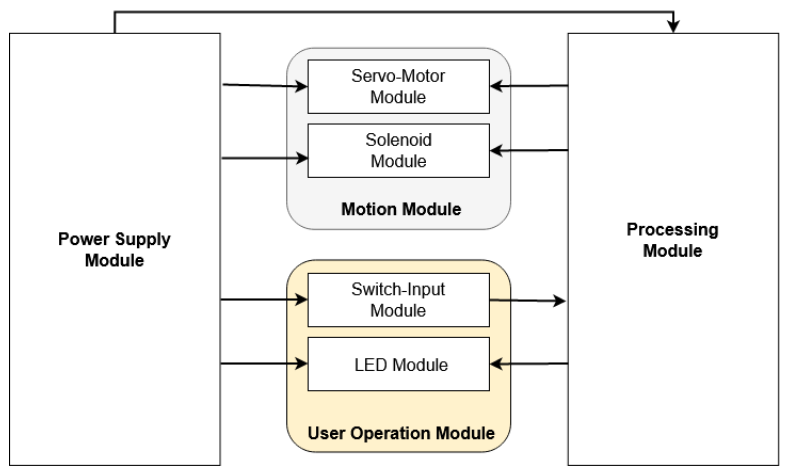

Figure 3. Overall Architecture of the ThamRobot System

\section{A. User Operation Module}

The user operation module of the system is a combination of two modules named switch-input module and LED module. This module is the only module that directly interacts with the user. The switch-input module represents two switches of the system such as ON/OFF switch and mode change switch. The first switch or the ON/OFF switch is used to switch ON and OFF the system while mode change switch is used to change the three drum tunes. Secondly, the LED module consists of three colored LEDs that represent three drum tunes. This module has been established for the user's convenience. This user operation module is very important module in this system as it takes the inputs or switch inputs from the user.

\section{B. Processing Module}

The processing module of the system can be defined as the heart of the system which is a PIC 16F877A microcontroller. This module uses microchip technology and contained the program of the system. Basically, this system has been programmed to play three drum tunes which are commonly played using the Thammattama. In addition, the hidden process of the processing module is shown by the figure 4 .

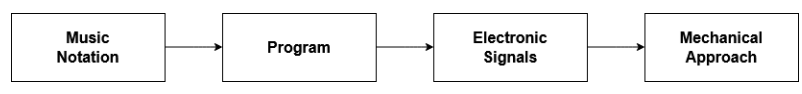

Figure 4. Process Flow the Processing Module
The significance of this system is, these two robotic arms are designed to play music. Music is a time-based, timedependent subject and accordingly, designing robotic arms that play music rather than other robotic arms is a challenging task. As the first step of the development, important characteristics factors such as the music notes of the Thammattama, drum type among two drums, number of drum sticks, drum locations, approximate amount of stress applied on the drum face to produce notes, playing technique, distance between the Thammattama stick (kadippu) and the drum face, frequency and pitch were identified. These characteristics factors are shown in the table 2 and 3. Secondly, using the processing module, these notes were declared by its solenoid values, servo-motor values and delays. These three values were different for each music note of the Thammattama. As the third step of the process, these notes were arranged according to a particular drum tune using a trial and error approach. Finally, these values were transmitted to the motion module as the output as a source of electronic signals.

\section{Motion Module}

The motion module of the system contains two modules such as solenoid module and the servo-motor module. This module is the module that performs approprite motions along $\mathrm{Y}$ and $\mathrm{X}$ axis. In the solenoid module there are two solenoids that one is connected to each arm. The internal solenoids of the contactor named LC1D180 has been used to move arms up and down direction along the $\mathrm{Y}$ axis. Similarly, system has two servo-motors named SM-166M that one is connected to each arm to move arms along $\mathrm{X}$ axis. The motion module takes the output of the processing module as the input to perform a mechanical approach to play a particular drum tune. Figure 5 shows the construction of the robotic arm.

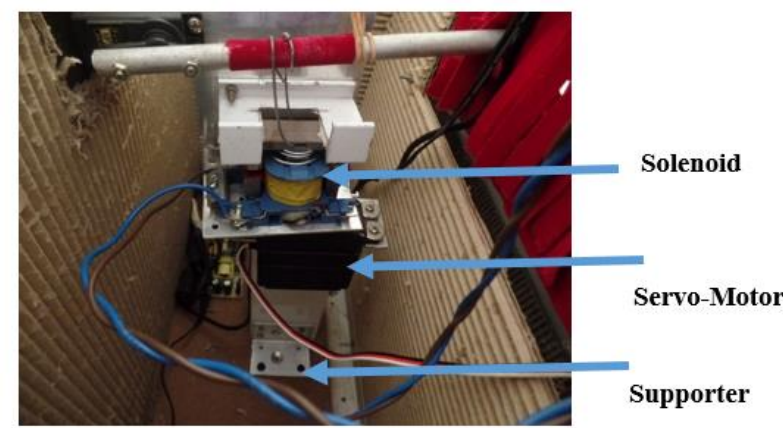

Figure 5. Construction of a Single Arm

The figure 6 and 7 shows the behavior of robotic arms along $\mathrm{Y}$ axis and $\mathrm{X}$ axis respectively.

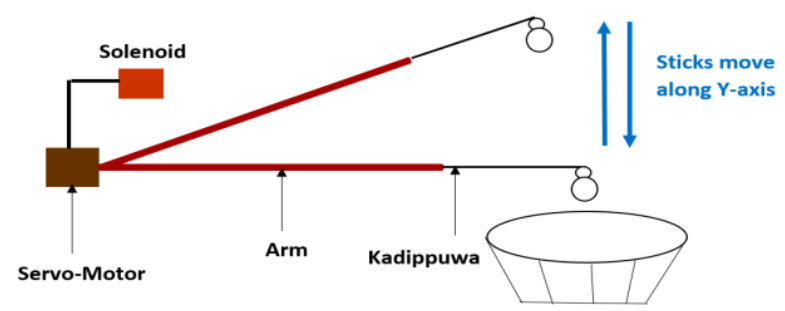


Figure 6. Behavior of Arms using Solenoids

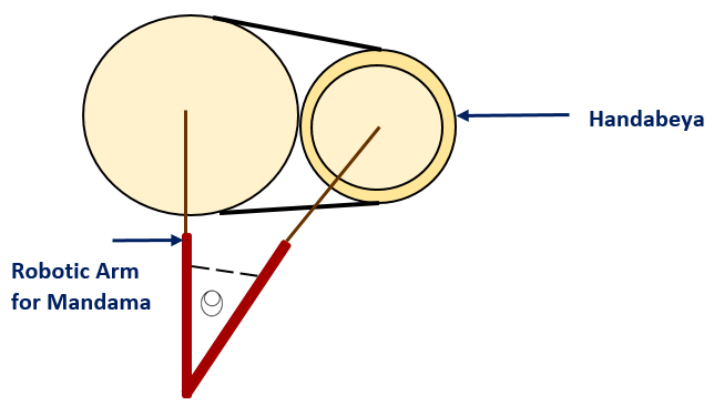

Figure 7. Behavior of Arms using Servo-Motors

According to the Table 3 that represents playing technique of notes of the Thammattama, it is clearly mentioned there are five different playing techniques. To achieve this task, the ThamRobot has been designed with all these five playing techniques as well as two other techniques. Figure 8. Shows the different combination position of arms.

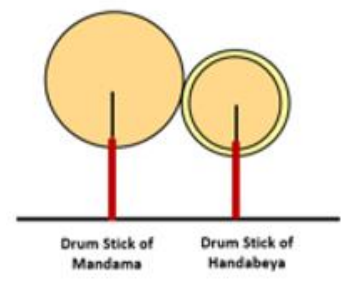

Arms Position 1

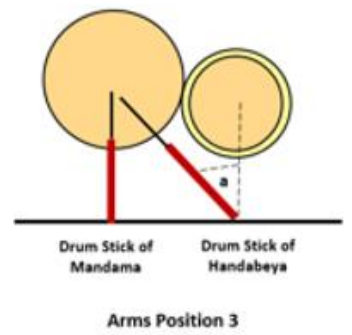

Figure 8. Different Combination Positions of Arms

\section{Power Supply Module}

The power supply module is the module that is connected with every module and component of the system to fulfil the power requirement. The power supply module is a combination of different components such as switch-mode power supplies (SMPS), voltage converters, linear regulators, diode bridges, connectors, and etc. At first, the system has been connected to a $230 \mathrm{~V}$ AC voltage and it will be converted into a $12 \mathrm{~V}$ AC voltage using a switch-mode power supply (SMPS). The output of the SMPS has been connected to a diode bridge that it a bridge of four diodes and the output coming from the diode bridge has been smoothed by two capacitors. This smoothened output will be then entered into a voltage regulator named LM317 and will be gone across a diode. After that, this ouput will be enetered into a LM7805 linear regulator that gives $5 \mathrm{~V}$ DC voltage. Mainly, it gives $5 \mathrm{~V}$ and $12 \mathrm{~V}$ DC voltages to operate components in the system.

The system works according to the user's input. At first, the user has to switch ON the system. When he switch ON, the default mode of the system is drum tune 1 . But after switch ON the system, the user can change the mode or change the drum tune. Then this input will be taken by the processing module and it sends the electronic signals to the solenoids and servo-motors to play the drum tune correctly, accurately and efficeintly. Advantage of this system is it plays a particular drum tune of the Thammattama until the user switch OFF the system or change the mode like a drum player without any intevention of a human being. In addition, this system plays drum tunes correctlty, efficiently by moving it arms very accurately with the time. The figure 9 and 10 shows the circuit board and developed system respectively.

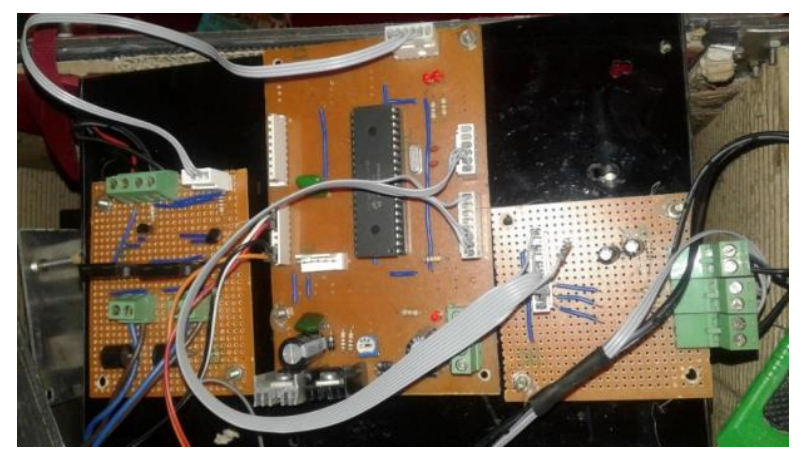

Figure 9. Circuit Board of the System

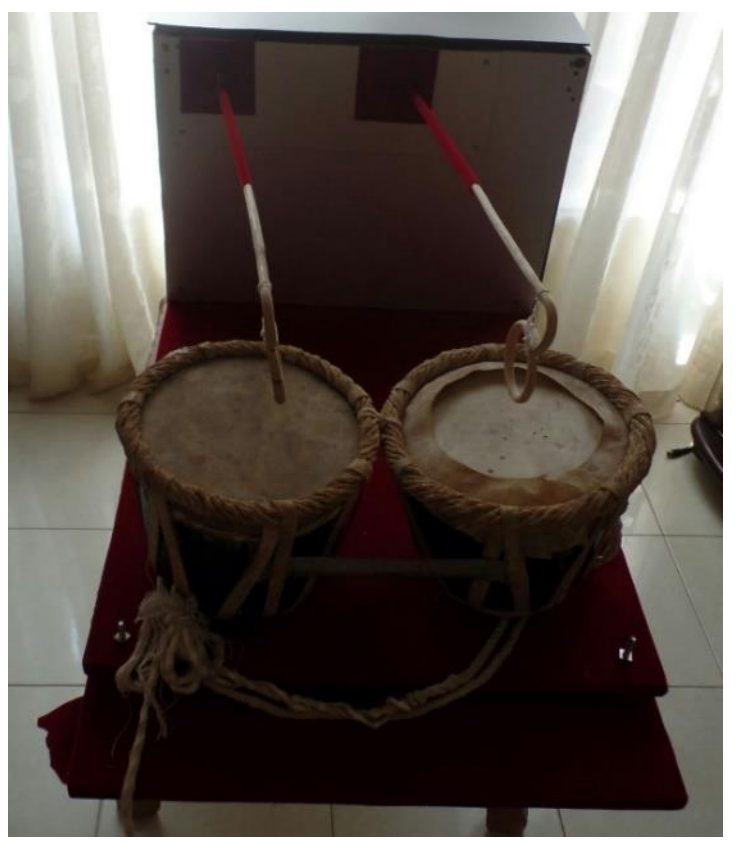

Figure 10. Automated Robotic System 


\section{RESULTS AND DISCUSSION}

The ThamRobot system has been evaluated by using two different tests in a laboratory environment. The first test has been done using human evaluators as this robotic system is an alternative for a traditional drum and people of Sri Lanka are extremely sensitive to this traditional music. Accordingly, the test experiment 1 was conducted using twenty-five people. As the testing components, the developed robotic system, recorded music and a drum player were used. Then, a same drum tune was played separately by recorded music, drum player and robotic system. As the restriction, these people were not able to see anything and the only thing left to do was to listen to this music and give marks for each of these drum tunes. The marks that were given by people were collected and the final evaluation graph is represents using graph 1.

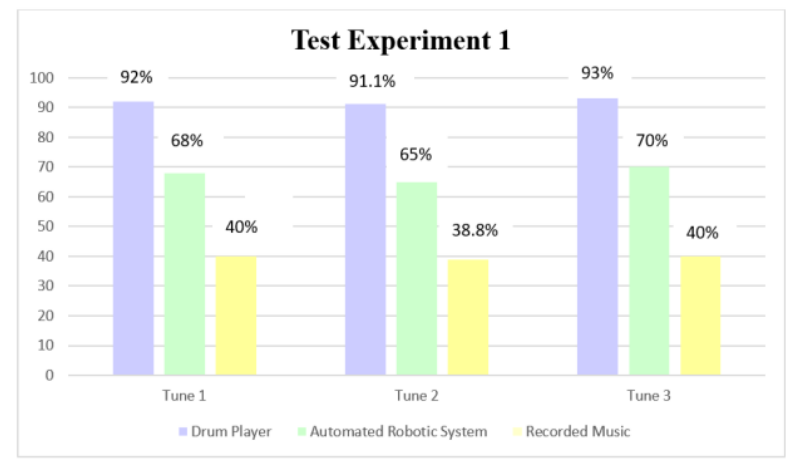

Graph 1. Evaluation Results of Test 1

The test experiment 1 was conducted using people in Sri Lanka and they have recognized the music differences of the music of drum player, automated robotic system and recorded music only hearing the music. Accordingly, the developed system is placed in between the drum player and the recorded music and have obtained an encouraging result for three drum tunes.

In music, there are four main attributes that are related with music notes of an any instrument. They are frequency, dynamics, timbre and texture. Among those four attributes, the test experiment 2 was carried out to check the correctness of the frequencies of the ten notes that can be played using the ThamRobot system. At the first step of the research, the standard frequencies of the notes have been identified and the data are mentioned in the table 2. Accordingly, in the test experiment 2 , a frequency counter has been used to measure the frequencies of the notes that can be played using the developed robotic system and the comparisson between the real frequency of the notes of the Thammattama and the frequencies detected by the frequency counter of the developed system are mentioned in the table 4 .

Table 4. Comparison between Frequencies

\begin{tabular}{ccc} 
Music Note & Real Frequency & Detected Frequency \\
\hline Don & $80 \mathrm{~Hz}$ & $78 \mathrm{~Hz}$ \\
Thon & $92 \mathrm{~Hz}$ & $91 \mathrm{~Hz}$ \\
Kun & $100 \mathrm{~Hz}$ & $100 \mathrm{~Hz}$ \\
Kita & $130 \mathrm{~Hz}$ & $127 \mathrm{~Hz}$ \\
Kruu & $110 \mathrm{~Hz}$ & $112 \mathrm{~Hz}$ \\
Thari & $112 \mathrm{~Hz}$ & $114 \mathrm{~Hz}$ \\
Thath & $157 \mathrm{~Hz}$ & $150 \mathrm{~Hz}$ \\
Gen & $95 \mathrm{~Hz}$ & $90 \mathrm{~Hz}$ \\
Raj & $91 \mathrm{~Hz}$ & $89 \mathrm{~Hz}$ \\
Digi & $122 \mathrm{~Hz}$ & $120 \mathrm{~Hz}$ \\
\hline
\end{tabular}

\section{CONCLUSION AND FURTHER WORKS}

The article presented the design and implementation of a robotic system that has two robotic arms that were designed to play the Thammattama which is one of the four major traditional drums in Sri Lanka. The system has been programmed to play three different drum tunes correctly and efficiently which are commonly played using the Thammattama without any intervention of a drummer. The system has been designed with the help of PIC 16F877A and microchip technology. In addition, to perform actuations along two axis such as $\mathrm{X}$ and $\mathrm{Y}$, solenoid and servo-motor technology have been used. The system tested and evaluated by carrying out two experiments using human evaluators and also detecting the correctness of the frequencies of the ten main notes of the drum. As further works of the research, it is proposed to develop the current automated system into a closed loop control system containing sensors that can detect faults of the sounds of the notes and automatically correct them. The current system has been only tested to evaluate the frequencies of the notes. The further testing will be carried out to test and compare the other remaining three attributes such as dynamics, timbre and texture.

\section{REFERENCES}

[1] K. Bandara, "Udarata Bera Wadana Kalawa", Sarasavi, 2017. [Online]. Available: https://www.sarasavi.lk/udaratabera-wadana-kalawa-9553008534.

[2] N. Dassenaike, "Sinhala folk music : its vocal traditions and stylistic nuances", ResearchGate, 2012. [Online]. Available:

https://www.researchgate.net/publication/320923633_Sinhala _folk_music_its_vocal_traditions_and_stylistic_nuances.

[3] S. Daniel, "Traditional Beats: Ten Uniquely Sri Lankan Drums", Roar.media, 2018. [Online]. Available: https://roar.media/english/life/history/traditional-beats-tenuniquely-sri-lankan-drums.

[4] N. Jasentuliyana, "The Unique Sights \& Sounds of Sri Lanka Come Alive in America - IDN-InDepthNews | Analysis That Matters", Indepthnews.net, 2019. [Online]. Available: https://www.indepthnews.net/index.php/the-world/usa-andcanada/2903-the-unique-sights-sounds-of-sri-lanka-comealive-in-america. 
[5] "Kandyan Drumming cultural features", Insightguides.com, 2021. [Online]. Available: https://www.insightguides.com/destinations/asia-pacific/srilanka/cultural-features/kandyan-drumming.

[6] "Traditional Drums", Lakpura, 2021. [Online]. Available: https://lakpura.com/traditional-drums.

[7] G. Ranathunga, "Art and tradition of Sri Lanka - Volume 01: Music of Sri Lanka", Dl.lib.uom.lk, 2021. [Online]. Available: http://dl.lib.uom.lk/handle/123/14436.

[8] C. Meddegoda, "The Story of a Failed Business Concept: Intensifying a Drum Production in Sri Lanka", ResearchGate, 2017. [Online]. Available: https://www.researchgate.net/publication/339913738_The_St ory_of_a_Failed_Business_Concept_Intensifying_a_Drum_Pr oduction_in_Sri_Lanka.

[9] "Rhythm and Moves with Sri Lankan drumming", Daily News, 2017. [Online]. Available: http://www.dailynews.lk/2017/06/09/features/118360/rhythmand-moves-sri-lankan-drumming.

[10 ] G. Peiris, "Beraya : Sri Lankawe Saha Lokaye Bera Pilibadha Wimasumak", Expographic Books, 2012. [Online]. Available: https://www.expo-graphic.com/books/Beraya--Sri-Lankawe-Saha-Lokaye-Bera-Pilibadha-Wimasumak9789552900099/view.

[11] "Dankutu Dankutu: The Making Of The Traditional Drum", Explore Sri Lanka - Once discovered, you must explore...... 2012. [Online]. Available: http://exploresrilanka.lk/2012/08/dankutu-dankutu-themaking-of-the-traditional-drum/.

[12] D. Blacker, "Traditional Drum Making In Sri Lanka: Beats down the Ages", Thuppahi's Blog, 2016. [Online]. Available: https://thuppahis.com/2016/12/30/traditional-drummaking-in-sri-lanka-beats-down-the-ages/.

[13] O. Koç, G. Maeda, and J. Peters, "Online optimal trajectory generation for robot table tennis," Rob. Auton. Syst., vol. 105, pp. 121-137, Jul. 2018, doi: 10.1016/j.robot.2018.03.012.

[14] B. Haugaløkken, M. Skaldebø and I. Schjølberg, "Monocular vision-based gripping of objects", ResearchGate, 2021. [Online]. Available: https://www.researchgate.net/publication/342129668_Monocu lar_vision-based_gripping_of_objects.

[15] W. Takano, H. Kanayama and T. Takahashi, "A datadriven approach to probabilistic impedance control for humanoid robots", ResearchGate, 2021. [Online]. Available: https://www.researchgate.net/publication/337056023_A_datadriven_approach_to_probabilistic_impedance_control_for_hu manoid_robots.

[16] A. SANCHETI, "Gesture Actuated Robotic
Arm", Ijsrp.org, 2021. [Online]. Available: http://www.ijsrp.org/research-paper-1212/ijsrp-p1261.pdf.

[17] M. Raj and R. Seamans, "Primer on artificial intelligence and robotics", Springer, 2021. [Online]. Available: https://link.springer.com/article/10.1186/s41469-019-0050-0.

[18] V. Patidar and R. Tiwari, "Survey of Robotic Arm and Parameters", ResearchGate, 2021. [Online]. Available: https://www.researchgate.net/publication/303749615_Survey_ of_Robotic_Arm_and_Parameters.

[19] A. Verma and A. Sharma, "Wireless Robotic ARM", Iosrjournals.org, 2021. [Online]. Available: https://www.iosrjournals.org/iosrjece/papers/Vol.\%209\%20Issue\%206/Version2/H09625053.pdf.

[20] M. Muhammed, M. Muji and M. Jenu, "MR 999-E Wireless Robotic Arm", Semantic Scholar, 2021. [Online]. Available: https://www.semanticscholar.org/paper/MR-999E-Wireless-Robotic-Arm-MuhammedMuji/c7fc8eeac08d42772d0f01b5abd38139de90212b.

[21] U. Mamodiya and P. Sharma, "Review in Industrial Automation", ResearchGate, 2021. [Online]. Available: https://www.researchgate.net/publication/314720788_Review _in_Industrial_Automation.

[22] R. Aparnathi, "The Novel of Six axes Robotic Arm for Industrial Applications", ResearchGate, 2021. [Online]. Available:

https://www.researchgate.net/publication/270723528_The_No vel_of_Six_axes_Robotic_Arm_for_Industrial_Applications $\backslash$.

[23] N. Kimura, K. Ito, T. Fuji and K. Fujimoto, "Mobile dual-arm robot for automated order picking system in warehouse containing various kinds of products", Ieeexplore.ieee.org, 2021. [Online]. Available: https://ieeexplore.iee.org/document/7404942.

[24] S. AR, "DESIGN AND IMPLEMENTATION OF ROBOTIC ARM USING PROTEUS DESIGN TOOL AND ARDUINO-UNO", ResearchGate, 2021. [Online]. Available: https://www.researchgate.net/publication/322790523_DESIG N_AND_IMPLEMENTATION_OF_ROBOTIC_ARM_USI NG_PROTEUS_DESIGN_TOOL_AND_ARDUINO-UNO.

[25] A. Rahman, A. Khan, T. Ahmed and M. Sajjad, "Design, Analysis and Implementation of a Robotic Arm-The Animator", ResearchGate, 2021. [Online]. Available: https://www.researchgate.net/publication/269690255_Design_ Analysis_and_Implementation_of_a_Robotic_ArmThe_Animator.

[26] R. Megalingam, G. Vivek, S. Bandyopadhyay and M. Rahi, "Robotic arm design, development and control for agriculture applications", Ieeexplore.ieee.org, 2021. [Online]. Available: https://ieeexplore.iee.org/document/8014623. 
[27] A. Kapur, "A HISTORY OF ROBOTIC MUSICAL INSTRUMENTS", ResearchGate, 2021. [Online]. Available: https://www.researchgate.net/publication/260387943_A_HIS TORY_OF_ROBOTIC_MUSICAL_INSTRUMENTS.

[28] T. Sobh and B. Wang, "Experimental Robot Musicians", Sci.utah.edu, 2021. [Online]. Available: https://www.sci.utah.edu/ beiwang/publications/Musician_Be iWang_2003.pdf.

[29] A. Kapur, T. Singer, A. Suleman and G. Tzanetakis, "A comparison of solenoid-based strategies for robotic drumming", ResearchGate, 2021. [Online]. Available: https://www.researchgate.net/publication/249874471_A_com parison_of_solenoid-based_strategies_for_robotic_drumming.

[30] S. Goonatilleke and B. Hettige, "Thambot: A Robotic Approach for Thammattama", Ir.kdu.ac.lk, 2021. [Online]. Available:

http://ir.kdu.ac.lk/bitstream/handle/345/2288/Abstract\%20Bo ok\%20Final\%20Version_158.pdf?sequence=1\&isAllowed=y.

[31] S. Goonatilleke and B. Hettige, "A Robotic Solution for Traditional Drums in Sri Lanka- Thammattama", Slaai.lk, 2021. [Online]. Available: https://slaai.lk/wpcontent/uploads/2021/03/2019-Proceedings/A-Robotic-

Solution-for-Traditional-Drums-in-Sri-Lanka-

Thammattama.pdf.

[32] "PIC16F87XA Data Sheet", Ww1.microchip.com, 2021. [Online]. Available: https://ww1.microchip.com/downloads/en/devicedoc/39582b. pdf. 